\title{
A green approach towards the production of Zinc Oxide scaffolds
}

\author{
Sudhir Kumar Sharma and Ramesh Jagannathan*
}

\begin{abstract}
We report a novel method for the fabrication of porous zinc oxide scaffolds by a scalable supercritical $\mathrm{CO}_{2}\left(\mathrm{sc}-\mathrm{CO}_{2}\right)$ based nebulization process. This process consists of mixing of sc- $\mathrm{CO}_{2}$ stream with zinc acetate solution under supercritical conditions. This process consists of evaporation of $\mathrm{CO}_{2}$ enriched water micro-droplets deposited from an aerosol onto heated substrates. Our process is readily scalable to produce zinc oxide scaffolds on a manufacturing scale.

Keywords-Zinc Oxide, scanning electron microscopy. Blue emission, Optical Properties, Supercrtitical Technologies
\end{abstract}

\section{Introduction}

The implementation of supercritical fluids based technologies has recently received significant interest from the scientific community with the aim to upgrade the traditional technologies as well as to develop new technologies for the production of smart materials. The characteristics of smart materials at micro-nano scale are closely associated with their chemical composition as well as to their particle size. The production of such materials with specific properties is very important for numerous applications in catalysis, coatings, electronics, ceramics, superconductors, dyestuff, pigments, and pharmaceuticals. In these fields, researchers are very active in improving the properties of these materials by adapting new processes and technologies including "green technologies".

\section{Experimental}

The schematic and process detail of our $\mathrm{CO}_{2}$ assisted nebulization process in our prior publication[1]-[4]. In brief, we mixed a continuous stream of supercritical carbon dioxide $\left(\mathrm{sc}-\mathrm{CO}_{2}\right)$ of pressure of 145 bar) with 0.1 wt $\%$ of zinc acetate solution prepared in Milli-Q water. This homogenous mixture is passed through a heat exchanger (temperature of $120^{\circ}$ C) and allowed to expand at atmospheric pressure via capillary tubing. Depressurization process created very fine and dense aerosols. The dense aerosol is deposited onto silicon substrates preheated at $140^{\circ}$ C. We varied to duration of deposition of scaffolds ranging from 10 to $30 \mathrm{~min}$.

Authors Name/s per Affiliation (Author)

New York University Abu Dhabi,

$U A E$.
Surface morphology of these scaffolds were analyzed by a field emission scanning electron microscope (FE- SEM, Quanta FEG 450) and atomic force microscope (Agilent 5500, Keysight technologies). A Shimadzu UVPC 1600 spectrophotometer was used to collect UV-vis reflectance spectra using a specular reflectance measurement attachment. Photo-luminescence excitation and emission spectra were collected using a Perkin Elmer (LS-55 Shimadzu) fluorescence spectrometer with a front surface accessory. WiTec alpha 300 Confocal Raman Microscope equipped was used for confocal Raman spectroscopy[5].

\section{Results and discussion}

We performed SEM imaging for zinc oxide scaffolds is shown in figure 1a. The scaffold morphology with 1-3 micron sized pores is consistent with our previous studies. Fig. 1b shows typical 3D AFM image of the same scaffold scanned in non-contact mode. We found that scaffold morphology is consistent with SEM studies.
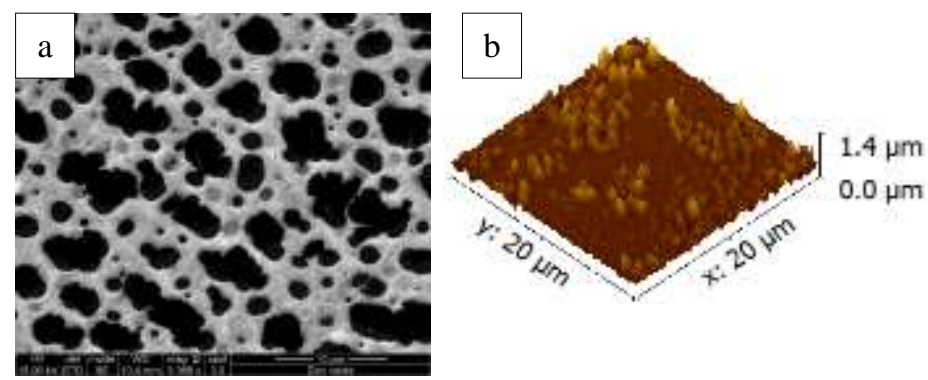

Figure 1. Morphology of zinc oxide scaffolds recorded by (a) SEM and using AFM in non-contact mode.

The band gap energy value of these scaffolds were evaluated from diffused reflectance plot using Tauc's plot (Fig. 2a) and found to be $3.25 \mathrm{eV}[6]$. This value is consistent with standard bulk zinc oxide values $(3.37 \mathrm{eV})[7]-[9]$.

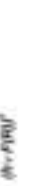

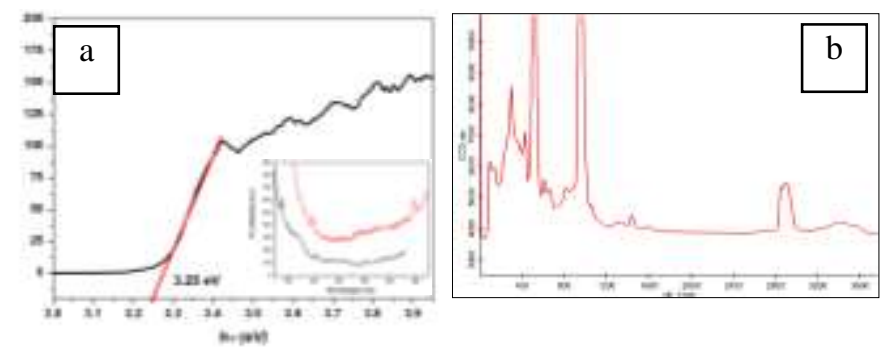

Figure 2. (a) Band gap values evaluated from diffused reflectance spectra of (inset show PL excitation and emission spectra) and (b) confocal Raman spectra recorded by $532 \mathrm{~nm}$ excitation for $\mathrm{ZnO}$ scaffolds. 
PL excitation and emission characteristics of scaffolds is shown in inset fig. 2a. Qualitatively, the excitation spectra (black ink) showed band edge excitation at $337 \mathrm{~nm}$. We collected emission spectra $\lambda_{\text {ext }}=337 \mathrm{~nm}$ (blue ink) by using excitation spectra as marker. Excitation at $337 \mathrm{~nm}$ resulted in a sharp near band edge (NBE) emission peak around $400 \mathrm{~nm}$, which is consistent with observations in the literature. Micro-Raman analysis shown in figure $2 b$ resulted a typical vibration modes $\left(410 \mathrm{~cm}^{-1}\right)$ of zinc oxide corresponding to polycrystalline zincite. We also observed some a small amount of zinc acetate at $666 \mathrm{~cm}^{-1}$ and at $2880 \mathrm{~cm}^{-1}$ band corresponding to $\mathrm{C}-\mathrm{H}$.

\section{Summary}

We report a novel method for the fabrication of zinc oxide scaffolds by a scalable supercritical $\mathrm{CO}_{2} \quad\left(\mathrm{sc}-\mathrm{CO}_{2}\right)$ based nebulization process, under mild processing conditions $(\mathrm{P}=145$ bar; $\mathrm{T}=110^{\circ} \mathrm{C}$ ). The process of drying on the heated substrate and the resulting 'coffee-ring effect' phenomenon produces $\mathrm{ZnO}$ scaffolds with typical pore size in the rage of 1-3 $\mu \mathrm{m}$. Optical characterizations such as band edge absorption and band gap values $(3.25 \mathrm{eV})$ confirmed the optical characteristics of zinc oxide. Photoluminescence emission (PLE) characteristics of as deposited scaffolds showed sharp NBE blue emissions. Our process is readily scalable to produce $\mathrm{ZnO}$ scaffolds on a manufacturing scale

\section{References}

[1] S. K. Sharma, T. Blanton, J. Weston, S. Khapli, and R. Jagannathan, "Sharp blue emission of $\mathrm{ZnO}$ crystals by supercritical CO2 processing," $J$. Supercrit. Fluids, vol. 110, pp. 176-182, 2016.

[2] R. Jagannathan, G. Irvin, T. Blanton, and S. Jagannathan, "Organic nanoparticles: Preparation, self-assembly, and properties," Adv. Funct. Mater., vol. 16, no. 6, pp. 747-753, 2006.

[3] R. Jagannathan and R. V. Mehta, "Continuous, atmospheric process to create organic clusters and nanostructured, functional films," Adv. Funct. Mater., vol. 16, no. 5, pp. 633-639, 2006.

[4] R. Jagannathan and G. C. Irvin, "Nanofluids: A new class of materials produced from nanoparticle assemblies," Adv. Funct. Mater., vol. 15, no. 9, pp. 1501-1510, 2005.

[5] S. K. Sharma, D. R. Nelson, R. Abdrabu, B. Khraiwesh, K. Jijakli, M. Arnoux, M. J. O’Connor, T. Bahmani, H. Cai, S. Khapli, R. Jagannathan, and K. Salehi-Ashtiani, "An integrative Raman microscopy-based workflow for rapid in situ analysis of microalgal lipid bodies," Biotechnol. Biofuels, vol. 8, no. 1, p. 164, 2015.

[6] S. K. Sharma, M. Vishwas, K. N. Rao, S. Mohan, D. S. Reddy, and K. V. a Gowda, "Structural and optical investigations of $\mathrm{TiO} 2$ films deposited on transparent substrates by sol-gel technique," $J$. Alloys Compd., vol. 471, no. 1-2, pp. 244-247, 2009.

[7] Ü. Özgür, Y. I. Alivov, C. Liu, a. Teke, M. a. Reshchikov, S. Doğan, V. Avrutin, S. J. Cho, and H. Morko, "A comprehensive review of $\mathrm{ZnO}$ materials and devices," J. Appl. Phys., vol. 98, no. 4, pp. 1103, 2005.

[8] U. Özgür, Y. I. Alivov, C. Liu, a. Teke, M. a. Reshchikov, S. Doğan, V. Avrutin, S.-J. Cho, and H. Morkoç, "A comprehensive review of $\mathrm{ZnO}$ materials and devices," J. Appl. Phys., vol. 98, no. 4, p. 041301, 2005.

[9] P. Jiang, J.-J. Zhou, H.-F. Fang, C.-Y. Wang, Z. L. Wang, and S.-S. Xie, "Hierarchical Shelled ZnO Structures Made of Bunched Nanowire Arrays," Adv. Funct. Mater., vol. 17, no. 8, pp. 1303-1310, May 2007. 